\title{
The Potential Relationship between the Incidence of Neurodegenerative Disease and Trace Mineral Composition in the Drinking Water of Rural Residents of Ontario
}

\author{
Avery R. Richer, Joanna N. Bil, John P. Cant, Vern R. Osborne \\ Department of Animal Biosciences, University of Guelph, Guelph, Ontario, Canada \\ Email: aricher@uoguelph.ca
}

How to cite this paper: Richer, A.R., Bil, J.N., Cant, J.P. and Osborne, V.R. (2017) The Potential Relationship between the Incidence of Neurodegenerative Disease and Trace Mineral Composition in the Drinking Water of Rural Residents of Ontario. Journal of Water Resource and Protection, 9, 881-889.

https://doi.org/10.4236/jwarp.2017.98059

Received: April 7, 2017

Accepted: June 30, 2017

Published: July 3, 2017

Copyright $\odot 2017$ by authors and Scientific Research Publishing Inc. This work is licensed under the Creative Commons Attribution International License (CC BY 4.0).

http://creativecommons.org/licenses/by/4.0/

\begin{abstract}
Many chronic degenerative diseases have been linked to high intake of various trace and heavy metals. The presence of these compounds in drinking water may be a significant contributing factor to total dietary intake and deposition, resulting in the propagation of a disease cascade. Dairy farm families residing in rural Ontario completed a survey pertaining to the health status of the individuals living on-farm. Water samples were also collected at each location and analyzed for mineral content. Out of 200 surveys delivered to farms, 134 were returned, which formed a study group comprised of 218 adult and 230 children participants. Taking into consideration several factors, such as genetics, environment and diet, the data were analyzed for correlations between heavy metal and mineral status and the prevalence of neurodegenerative diseases. The findings from this study suggest phosphorus, potassium and magnesium concentrations may play a role in the development of neurodegenerative diseases. Total hardness and $\mathrm{pH}$ of water may also have an impact on the development of these diseases.
\end{abstract}

\section{Keywords}

Trace Metals, Heavy Metals, Minerals, Neurodegenerative Disease, Water Quality

\section{Introduction}

The prevalence of a variety of chronic disease states is on the rise, with investigation into the causes of these conditions becoming a priority in human health research. Conditions such as Multiple Sclerosis, Parkinson's Disease, Alzheimer's Disease, Amytrophic Lateral Sclerosis (Lou Gehrig's Disease), Huntington's dis- 
ease, and Creutzfeldt-Jakob Disease are of concern in today's society, with over 260,000 cases reported in Canada in 2012 [1] [2]. In particular, Alzheimer's has been observed to have the most extreme increase in occurrence over the years, with approximately $42 \%$ of the reported cases representing those individuals in Canada that have been diagnosed with the disease or Alzheimer-related dementia states [1] [2].

Although researchers have confirmed an underlying genetic component for many of the health disorders seen today-including those pertaining to the central nervous system (CNS) focus has shifted to studying any existing environmental factors that may also play an important role. Lately, strong links have been noted between minerals in the soil and water, and the development of chronic degenerative conditions [3] [4] [5] [6]. Ions of trace and heavy metals such as iron, manganese, aluminum, mercury, lead, copper, chromium and cadmium have been linked to the initiation of numerous neurodegenerative disorders [1] [7] [8]. Iron especially has received attention with regards to Parkinson's, Alzheimer's and multiple sclerosis; researchers have localized the ion's accumulation to regions of the brain that have been recognized to undergo deterioration in these disease states [9] [10]. Peripheral and central nervous system regions which are notably affected include the spinal motor neurons for ALS, the cortex, basal forebrain, brain stem, and hippocampus in Alzhemier's, the cortex, substantia nigra, and locus ceruleus for Parkinson's, and the cortex, basal ganglia and striatum for Huntington's disease [11]. The number of other metal types that pose an increased risk are characteristic to each disorder; zinc, mercury, aluminum, and copper also appear to be involved in Alzheimer's, manganese, lead and copper in Parkinson's, lead and copper in ALS, and copper in Huntingon's [11] [12].

Existing research dictates that multiple interwoven factors, such as genetics, environment and diet influence an individual's health status and the expression of a disease state [3] [4] [5] [6]. Abnormalities at the genetic level have been proven to be largely influential in disorders of the brain like Parkinson's, Alzheimer's and Multiple Sclerosis [9] [10]. However, this does not discount the important role that heavy metals can play during the manifestation of these disorders; studies have pinpointed various malfunctioning metal ion carriers that appear to be involved. While many suggest that oxidative damage caused by metals can, in fact, influence proteins at the genetic level thereby affecting the expression and functioning of metal carriers, others argue that metal accumulation occurs possibly secondary to these physiological errors [11] [12]. Regardless of the mechanism, we believe heavy metal accumulation to be a an important player in chronic disease states, contributing largely to the progression and extent of neuronal degeneration in conditions like Parkinson's, Alzheimer's, Multiple Sclerosis and others. Furthermore, following analysis of our data we expect to see a correlation between disease prevalence and water quality; areas showing water contaminated with particularly high concentrations of heavy metals should present greater numbers of diagnosed individuals. 
At present, approximately ninety percent of Ontario's rural residents rely on groundwater as their main water source, which is accessed through wells [13]. The relationship between the mineral composition of water and the underlying regional geology thus cannot be ignored when considering the relationship between minerals and disease status. On average, adults consume $1200 \mathrm{~mL}$ of water daily [14], and the minerals obtained through this intake must not be discounted.

Investigations into the relationship between minerals in drinking water on dairy farms in Ontario, and the health status of the individuals residing on those farms were carried out during this study. The purpose of the study is to determine whether water mineral concentrations are associated with disease prevalence. Information regarding the health of dairy farm families was obtained through a survey, and water samples were collected at each farm location so that mineral intake through drinking water could be statistically linked to disease prevalence.

\section{Methods}

\subsection{Study Population}

A cross-sectional survey was conducted in rural areas of western, central, and eastern province of Ontario, Canada. All participants were residing on dairy farms and were asked to consent to the completion of a written survey, returned by mail in an envelope provided by the researchers. Of the 200 surveys that were delivered to the dairy farmers, 134 surveys (67\%) were completed and returned. Through the 134 surveys returned, information was gathered on 218 adults and 230 children on dairy farms across the province of Ontario.

The surveys, as well as the consent form, were approved by the University of Guelph Research Ethics Committee HS-098, and participants were asked to provide written informed consent on behalf of themselves and their children.

\subsection{Water Sampling}

Water samples were collected from all 200 farms as part of a larger study, while researchers were on farm conducting interviews with the farm family. Samples were taken directly from faucets that the family used for drinking and meal preparation, in $500 \mathrm{~mL}$ bottles supplied by Agri-Food Laboratories in Guelph, Ontario. The water samples were taken to Agri-Food Laboratories, where a complete mineral analysis $(\mathrm{pH}$, nitrate nitrogen, phosphorus, potassium, magnesium, calcium, chloride, sulphate, total salt, bicarbonate sodium, total dissolved solids, total hardness, zinc, manganese, copper, iron, boron and silicon) was performed on each sample by inductively coupled mass spectrometry.

\subsection{Questionnaire Contents}

The questions posed in the survey were designed to assess the health of dairy farm residents in relation to water chemical quality. Questions considered the influence of both environmental and genetic factors on the health status of these 
individuals. The prevalence of various diseases, as well as chronic conditions and diagnosed disabilities were assessed through the survey. Questions pertained to both adults and children of the farm families, with a small number of questions specifically directed towards assessing the learning capabilities of children. During an on-farm visit with the participants, an interview was conducted and information was obtained regarding the ages of both adults and children living on each farm.

Questions regarding the on-farm water source, the consumption of water on-farm, the frequency of purchase of bottled water, and the colour, odour, and clarity of the water were also asked in the survey.

\subsection{Statistical Analysis}

The following statistical methods were used in the analysis of data pertaining to the water sample test results and health survey results:

A series of $\mathrm{t}$-tests/Wilcoxon tests (geographical location vs. water mineral concentrations, disease prevalence vs. water mineral concentrations, total number of reported illnesses vs. geographical location), and chi-square tests/Fisher's exact tests (geographical location vs. disease prevalence) were carried out. All analyses were conducted using The SAS System v. 9.1.3.

Water mineral concentrations and $\mathrm{pH}$ were recorded in their appropriate units. Disease prevalence was recorded as a count (i.e. the number of respondents at each location reporting a specific pre-determined subcategory of illness; neurological disease, cancer, respiratory conditions, cardiovascular disease, gastrointestinal disease, or skin disorders). Since very few respondents reported any of these conditions and even fewer respondents reported multiple occurrences either within or across subcategories, these outcomes were converted to binary events (i.e. presence vs. absence of a particular subtype of disease). Additionally, the presence of "any disease" (defined as the presence of at least one of the aforementioned disease categories) and the total number of diseases reported (defined as the sum of the counts across each of the individual disease subcategories) were investigated.

In order to uncover any potential correlation between the incidence of neurological disease the survey participants and mineral content of drinking water in corresponding regions a logistic regression model was applied to the data set. Since major effect may relate to several factors, including characteristics of each person (age, sex), farm water supply (mineral content, age of well), specific watershed and the dairy herd on the farm (incidence of conditions among the herd), we ensured that these effects were accounted for and chose to model them by means of fixed effects.

The following formula was applied to the data set:

$$
\log \operatorname{it}\left(Y_{i j k}\right)=X * \text { Beta }+u_{i}+v_{j}
$$

where $Y_{i j k}$ represents the health status of participants ( $i$-th family, $j$-th farm, $k$-th person), $X$ is a matrix of the regression matrix, which includes all predictors of 
the model (age, sex, herd size), and Beta is a vector of the unknown effects of the predictors for the occurrence of neurological diseases in humans. The $u_{i}$ represents any uncorrelated random effects, which signal family effects that could be related to lifestyle (i.e. do individuals drink tap water, coffee, tea or not so much) or to genetics. We have assumed that families are independent; although there may be few related through marriage, the sample size would likely be too small to investigate this further with the data we have collected for the present study. The $v_{j}$ represents a second random effect that would model environmental effects due to farm location. Even if several wells tap the same aquifer, the drinking water would still exhibit variation in its mineral content. Thus, we have chosen to model the local variation in water mineral content via spatially correlated random effects. We would expect to see a spatial effect, whereby nearby farms are more similar than those further away.

\section{Results}

\section{Disease Incidence vs. Water Mineral Concentrations}

A summary of the water mineral concentrations stratified by disease incidence is provided in Table 1. Water mineral concentrations are summarized by their median, minimum, and maximum values due to the skewed nature of their distributions. Associations between water mineral concentrations and disease incidence were tested through a series of Wilcoxon tests. The $\mathrm{pH}$ is summarized by its mean and standard deviation and associations between $\mathrm{pH}$ and disease incidence are determined through a series of t-tests.

Table 1 finds evidence to suggest that phosphorus, potassium, and magnesium concentrations are significantly higher in farms reporting incidence of neurological disease than among farms in which this type of illness is absent. Total hardness is also marginally higher in farms with reports of neurological disease, but this finding did not quite reach statistical significance. $\mathrm{pH}$ is significantly lower in farms reporting neurological disease than in those in which neurological disease is absent.

Table 1. Water mineral concentrations versus neurological disease incidence.

\begin{tabular}{|c|c|c|c|}
\hline \multirow{2}{*}{ Characteristic } & \multicolumn{2}{|c|}{ Neurological disease } & \multirow{2}{*}{$\begin{array}{c}\text { Statistical } \\
\text { significance }\end{array}$} \\
\hline & Absent & Present & \\
\hline Number of cases & $\mathrm{n}=118$ & $\mathrm{n}=16$ & $\mathrm{n} / \mathrm{a}$ \\
\hline $\mathrm{pH}($ mean $+/-\mathrm{SD})$ & $7.56+/-0.25$ & $7.39+/-0.23$ & $p=0.0141$ \\
\hline Total hardness $\left(\mathrm{ppm}^{b}\right)$ & $238.11(1.00,2659.81)$ & $322.49(79.31,1993.42)$ & $p=0.0843$ \\
\hline Phosphorus $\left(\mathrm{ppm}^{b}\right)$ & $0.10(0.10,2.62)$ & $0.10(0.10,1.44)$ & $p=0.0211$ \\
\hline Potassium $\left(\mathrm{ppm}^{b}\right)$ & $0.10(0.10,29.18)$ & $1.74(0.10,25.53)$ & $p=0.0146$ \\
\hline Magnesium $\left(\mathrm{ppm}^{b}\right)$ & $22.41(0.10,454.40)$ & $30.84(9.22,224.85)$ & $p=0.0381$ \\
\hline Manganese $\left(\mathrm{ppm}^{b}\right)$ & $0.01(0.01,1.68)$ & $0.02(0.01,0.12)$ & $p=0.3861$ \\
\hline Iron $\left(\mathrm{ppm}^{b}\right)$ & $0.12(0.01,3.81)$ & $0.07(0.01,0.73)$ & $p=0.5546$ \\
\hline
\end{tabular}

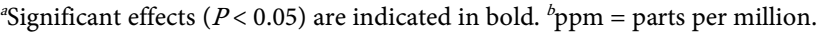




\section{Discussion}

In this study, we examined water mineral content and health status of individuals living on farm from a variety of properties in rural Ontario. Our results suggest that mineral composition in drinking water on farms in Ontario may affect the prevalence of disease. Since many chronic degenerative diseases have been linked to high intake of various trace and heavy metals, the presence of these compounds in drinking water may be a significant contributing factor to intake and deposition, results in the propagation of a disease cascade.

In the present study, increased mineral concentrations in drinking water increase the incidence of neurological disease suggest that environmental factors affect the CNS. Increased levels of phosphorus, potassium and magnesium were associated with an increased prevalence of neurodegenerative diseases. Previous studies found when comparing clusters against metal concentrations in rural regions those regions containing individuals with greater incidence of mental retardation or delayed development were also found to contain higher concentrations of heavy metals [4] [5]. Oyoo-Okoth et al. (2013) also found geologically enriched environments to be a contributor to high metal exposure in children; soil, water and locally grown food were all considered contaminated mediums through which exposure had likely occurred.

As with any condition, certain populations and individuals are more susceptible to the consequences of heavy metal exposure; due to the risks of transplacental transfer and the physiology of younger persons, pregnant women and children are particularly susceptible [5] [6] [15] [16]. More recently, research has indicated that child developmental disorders such as autism may have an auto-immune component associated with excess dietary iron [17]. Others have linked high lead exposure with behavioural and cognitive issues in children [18] [19] [20] [21]. Correlations have been recently noted for geographical areas of greater heavy metal load and the incidence of mental retardation and developmental delay in individuals living in these areas [4]. Recent studies have indicated higher heavy metal exposure in more industrialized areas that are heavily populated [5] [16]; however, exposure from particular sources, such as environmental soil and ground water, may actually be greater for individuals residing in rural regions [4] [6].

Metal ions contribute to the development of diseases through the role they play in free radical formation and oxidative damage, which ultimately leads to tissue degeneration [8] [15]. Reactive oxygen species can be deleterious to essential proteins, causing denaturation. Damage to the ubiquitin-proteasome system can also occur, resulting in aggregation and accumulation of defective proteins due to lack of protein clearance [11] [22]. Free radical formation occurs at a greater rate in certain areas of the brain, making these regions more susceptible to damage ensued by the processes that take place, like the Fenton reaction [9] [23]. Metal exposure can cause genetic damage, as well as influence reactivation or silencing of gene expression [11] [24]. Metals can also cause damage via nonoxidative means, by binding to DNA and forming adducts [11] [24]. 
Padhye (2003) argues that the incidence of Autism in today's society is a result of excess dietary exposure to metals such as iron in early childhood; there appears to be a relationship between the enhanced iron fortification of infant foods in certain countries, and the increase in childhood disorders within those areas. Iron accumulation in the brain has been associated with symptoms like hyperactivity, attention deficit, depression and anxiety [17]. Recently, a number of studies have indicated that there may be an auto-immune component influencing autism pathogenesis [25] [26] [27]. Padhye (2003) suggests that iron acts as an immune system modulator, whereby higher than usual concentrations of the metal result in a hyperactive immune response which can lead to auto-immune disorders. Furthermore, physical symptoms such as gastro-intestinal issues, abnormal liver values, dermatitis, and asthma, which are typically displayed by autism patients, may in fact be due to a hyperactive immune response to iron overload in the associated tissues [17]. Nataf et al. (2006) found superior levels of various biomarkers indicative of environmental toxicity in the urine of autistic children; in particular, a molecular indicator of heavy metal overload called precoproporphyrin was higher when compared to control. Nataf et al. (2006) reported a considerable reduction in these biomarkers for the group of autistic children that was supplemented with dimercaptosuccinic acid (DMSA)-a heavy metal chelator [28].

\section{Conclusion}

The results of our study display a potential trend, linking water mineral accumulation to the development of neurodegenerative disorders. Based on latest research relating the two, it is likely that heavy metal accumulation occurs as a secondary effect and contributes largely to the progression and extent of neuronal degeneration in affected individuals. These results further stress the influence of environmental factors, as they pertain to drinking water quality, on the long-term health of humans. Not only are the microbial components of drinking water important, but also the chemical composition. Future studies comparing national data on neurodegenerative disease prevalence by province and region to mineral rock deposit profiles from corresponding regions of Canada would be useful.

\section{Conflict of Interest}

The authors report no conflict of interest.

\section{References}

[1] McBride, M. (2004) Neural Degenerative Diseases and the Environment, the Soil Health Link. In: Ackerman, J.D. and Chesworth, W., Eds., Health and the Planet, Faculty of Environmental Sciences: University of Guelph, Vol. 5, 31-52.

[2] Statistics Canada (2012) Canadian Community Health Survey: Neurological Conditions Prevalence Files, 2010/2011. Table 105-1300. CANSIM Canadian Socio-Economic Information Management System.

[3] Davies, B.E. (1994) Trace Elements in the Human Environment: Problems and 
Risks. Environmental Geochemistry and Health, 16, 97-106. https://doi.org/10.1007/BF01747905

[4] Aelion, C.M., Davis, H.T., McDermott, S. and Lawson, A.B. (2008) Metal Concentrations in Rural Topsoil in South Carolina: Potential for Human Health Impact. Science of the Total Environment, 402, 149-156.

https://doi.org/10.1016/j.scitotenv.2008.04.043

[5] Aelion, C.M., Davis, H.T., McDermott, S. and Lawson, A.B. (2009) Soil Metal Concentrations and Toxicity: Associations with Distances to Industrial Facilities and Implications for Human Health. Science of the Total Environment, 407, 2216-2223. https://doi.org/10.1016/j.scitotenv.2008.11.033

[6] Oyoo-Okoth, E., Admiraal, W., Osano, O., Manguya-Lusega, D., Ngure, V., Kraak, M.H.S., Chepkirui-Boit, V. and Makwali, J. (2013) Contribution of Soil, Water and Food Consumption to Metal Exposure of Children from Geological Enriched Environments in the Coastal Zone of Lake Victoria, Kenya. International Journal of Hygiene and Environmental Health, 216, 8-16.

https://doi.org/10.1016/j.ijheh.2012.05.004

[7] Bush, A.I. (2003) The Metallobiology of Alzheimer's Disease. Trends in Neurosciences, 26, 207-214. https://doi.org/10.1016/S0166-2236(03)00067-5

[8] Barnham, K.J. and Bush, A.I. (2008) Metals in Alzheimer's and Parkinson's Diseases. Current Opinion in Chemical Biology, 12, 222-228. https://doi.org/10.1016/j.cbpa.2008.02.019

[9] Sipe, J.C., Lee, P. and Beutler, E. (2002) Brain Iron Metabolism and Neurodegernative Disorders. Developmental Neuroscience, 24, 188-196. https://doi.org/10.1159/000065701

[10] Stankiewicz, J., Panter, S.S., Neema, M., Arora, A., Batt, C. and Bakshi, R. (2007) Iron in Chronic Brain Disorders: Imaging and Neurotherapeutic Implications. Neuropathics, 4, 371-386. https://doi.org/10.1016/j.nurt.2007.05.006

[11] Migliore, L. and Coppede, F. (2009) Environmental-Induced Oxidative Stress in Neurodegenerative Disorders and Aging. Mutation Research, 674, 73-84. https://doi.org/10.1016/j.mrgentox.2008.09.013

[12] Rivera-Mancia, S., Perez-Neri, I., Rios, C., Tristan-Lopez, L., Rivera-Espinosa, L. and Montes, S. (2010) The Transition Metals Copper and Iron in Neurodegenerative Diseases. Chemico-Biological Interactions, 186, 184-199.

https://doi.org/10.1016/j.cbi.2010.04.010

[13] Stone, R.P. and Myslik, J.P. (2007) Assessing the Potential for Ground Water Contamination on Your Farm. Ontario Ministry of Agriculture, Food and Rural Affairs, Toronto.

[14] Health and Welfare Canada (1990) Nutrient Recommendations. Minister of Supply and Services Canada, Toronto.

[15] Calderon, J., Ortiz-Perez, D., Yanez, L. and Diaz-Barriga, F. (2003) Human Exposure to Metals: Pathways of Exposure, Biomarkers of Effect, and Host Factors. Ecotoxicology and Environmental Safety, 56, 93-103. https://doi.org/10.1016/S0147-6513(03)00053-8

[16] Chabukdhara, M. and Nema, A.K. (2013) Heavy Metals Assessment in Urban Soil around Industrial Clusters in Ghaziabad, India: Probabilistic Health Risk Approach. Ecotoxicology and Environmental Safety, 87, 57-64. https://doi.org/10.1016/j.ecoenv.2012.08.032

[17] Padhye, U. (2003) Excess Dietary Iron Is the Root Cause for Increase in Childhood Autism and Allergies. Medical Hypotheses, 61, 220-222. https://doi.org/10.1016/S0306-9877(03)00126-9 
[18] Bellinger, D., Leviton, A., Allred, E. and Rabinowitz, M. (1994) Pre- and Post-Natal Lead Exposure and Behaviour Problems in School-Aged Children. Environmental Research, 66, 12-30. https://doi.org/10.1006/enrs.1994.1041

[19] Needleman, H.L., Riess, J.A., Tobin, M.J., Biesecker, G.E. and Greenhouse, J.B. (1996) Bone Lead Levels and Delinquent Behaviour. Journal of the American Medical Association, 275, 363-369. https://doi.org/10.1001/jama.1996.03530290033034

[20] Canfield Jr., R.L., Cory-Slechta, H.C.R., Cox, D.A.C., Jusko, T.A. and Lanphear, B.P. (2003) Intellectual Impairment in Children with Blood Lead Concentrations below $10 \mu \mathrm{g}$ per Decilitre. The New England Journal of Medicine, 348, 1517-1526. https://doi.org/10.1056/NEJMoa022848

[21] Lanphear, B.P., Homung, R., Khoury, J., Yolton, K., Baghurst, P., Bellinger, D.C., Canfield, R.L., Dietrich, K.N., Bornschein, R., Greene, T., Rothenber, S.J., Needleman, H.L., Schnaas, L., Wasserman, G., Graziano, J. and Roberts, R. (2005) LowLevel Environmental Lead Exposure and Children's Intellectual Function: And International Pooled Analysis. Environmental Health Perspectives, 113, 894-899. https://doi.org/10.1289/ehp.7688

[22] Crichton, R.R., Dexter, D.T. and Ward, R.J. (2008) Metal Based Neurodegenerative Disease-From Molecular Mechanisms to Therapeutic Strategies. Coordination Chemistry Reviews, 252, 1189-1199. https://doi.org/10.1016/j.ccr.2007.10.019

[23] Hirsch, E. and Faucheux, B. (1998) Iron Metabolism and Parkinson's Disease. Movement Disorders, 13, 39-45.

[24] Salnikow, K. and Zhitkovich, A. (2008) Genetic and Epigenetic Mechanisms in Metal Carcinogenesis and Cocarcinogenesis: Nickel, Arsenic, and Chromium. Chemical Research in Toxicology, 21, 28-44. https://doi.org/10.1021/tx700198a

[25] Singh, V.K., Warren, R., Averett, R. and Ghaziuddin, M. (1997) Circulating Autoantibodies to Neuronal and Glial Filament Proteins in Autism. Pediatric Neurology, 17, 88-90. https://doi.org/10.1016/S0887-8994(97)00045-3

[26] Comi, A.M., Zimmerman, A.W., Frye, V.H., Law, P.A. and Peeden, J.N. (1999) Familial Clustering of Autoimmune Disorders and Evaluation of Medical Risk Factors in Autism. Journal of Child Neurology, 14, 388-394. https://doi.org/10.1177/088307389901400608

[27] Mostafa, G.A. and Kitchener, N. (2009) Serum Anti-Nuclear Antibodies as a Marker of Autoimmunity in Egyptian Autistic Children. Pediatric Neurology, 40, 107112. https://doi.org/10.1016/j.pediatrneurol.2008.10.017

[28] Nataf, R., Skorupka, C., Amet, L., Lam, A., Springbett, A. and Lathe, R. (2006) Porphyrinuria in Childhood Autistic Disorder: Implications for Environmental Toxicity. Toxicology and Applied Pharmacology, 214, 99-108.

https://doi.org/10.1016/j.taap.2006.04.008 
Submit or recommend next manuscript to SCIRP and we will provide best service for you:

Accepting pre-submission inquiries through Email, Facebook, LinkedIn, Twitter, etc. A wide selection of journals (inclusive of 9 subjects, more than 200 journals)

Providing 24-hour high-quality service

User-friendly online submission system

Fair and swift peer-review system

Efficient typesetting and proofreading procedure

Display of the result of downloads and visits, as well as the number of cited articles Maximum dissemination of your research work

Submit your manuscript at: http://papersubmission.scirp.org/

Or contact jwarp@scirp.org 